\title{
UPAYA MENINGKATKAN HASIL BELAJAR IPA MELALUI PENERAPAN MEDIA PEMBELAJARAN BERBASIS MULTIMEDIA PESERTA DIDIK
}

\author{
Ade S. Permadi \\ Muchlis Saini \\ Universitas MuhammadiyahPalangkaraya
}

\begin{abstract}
Abstrak: Penelitian ini bertujuan :(1) Untuk mendeskripsikan aktivitas belajar peserta didik kelas Vb MI Darul Ulum Palangka Raya dalam pembelajaran IPA tentang pesawat sederhana dengan penerapan media pembelajaran berbasis multimedia. (2) Untuk mendeskripsikan hasil belajar IPA peserta didik apakah ada peningkatan saat menerapkan media pembelajaran berbasis multimedia. Metode yang digunakan peneliti adalah menggunakan rancangan Penelitian Tindakan Kelas (PTK) yang berusaha memecahkan atau menjawab permasalahan yang dihadapi sekarang. Yang menjadi subyeknya dalam penelitian ini peserta didik kelas Vb MI Darul Ulum Palangkara Raya sebanyak 31 orang. Untuk teknik pengumpulan data yang digunakan adalah tes, observasi, dan dokumentasi. Sedangkan analisis data dalam penelitian ini menggunakan rata-rata dan persentase. Dari hasil penelitian disimpulkan bahwa (1) Aktivitas belajar peserta didik kelas Vb MI Darul Ulum Palangka Raya lebih aktif pada saat pembelajaran Ilmu Pengetahuan Alam (IPA) dengan menggunakan Media Multimedia pada siklus I mencapai 2,95 dikategorikan cukup dan siklus II mencapai 3,75 dikategorikan baik. (2) Ada peningkatan hasil belajar IPA dengan Penerapan media Pembelajaran Berbasis Multimedia pada peserta didik kelas Vb MI Darul Ulum Palangka Raya. Hal ini terlihat dari data hasil belajar peserta didik pada siklus I mencapai 83,87\% dan pada siklus II meningkat menjadi 100\%. Adapun standar ketuntasan yang ditentukan sekolah untuk pelajaran Ilmu Pengetahuan Alam (IPA) yaitu 60.
\end{abstract}

Kata Kunci: Pembelajaran, IPA, Media, Multimedia.

\section{PENDAHULUAN}

Menurut Munid (Daryanto,2010:1) 'Pendidikan adalah usaha sadar dan sistematis, yang dilakukan orang-orang yang diserahi tanggung jawab untuk mempengaruhi peserta didik agar mempunyai sifat dan tabiat sesuai dengan cita-cita pendidikan". Menurut Purwanto (Daryanto,2010:1) "Pendidikan ialah pimpinan yang diberikan dengan sengaja oleh orang dewasa kepada anak-anak dalam pertumbuhannya (jasmani dan rohani) agar berguna bagi diri sendiri dan bagi masyarakat". Dalam arti lain, pendidikan merupakan pendewasaan peserta didik agar dapat mengembangkan bakat, potensi, dan keterampilan yang dimiliki dalam menjalani kehidupan, oleh karena itu sudah seharusnya pendidikan didesain guna memberikan pemahaman serta meningkatkan prestasi belajar peserta didik.

Melihat perkembangan zaman yang semakin modern, canggih, dan perkembangan ilmu pengetahuan yang semakin pesat. Hal ini adanya berbagai inovasi-inovasi baru yang media berbasis multimedia. Perkembangan ini berdampak pada sistem pendidikan di seluruh dunia dan juga berdampak pada sistem pendidikan di Indonesia. Teknologi berbasis multimedia dapat mempermudah guru dalam proses membelajaran sehingga sering digunakan dalam memaparkan materi pembelajaran. 
Media pembelajaran berbasis multimedia menjadi langkah sebagai media yang di ambil kerena mempunyai alasan: pelajaran akan lebih menarik, mudah dimengerti, guru dapat mengkombinasikan lebih dari dua media secara bersamaan, dapat mengkolaborasikan strategi satu dengan yang lainnya, lebih menarik perhatian peserta didik karena mereka dapat melihat, mendengarkan, dan sekaligus dapat memberikan motivasi kepada mereka. Sebagaimana hal ini senada dengan pendapat Obliger (Munir,2013:2) "Mendefinisikan multimedia merupakan penyatuan dua atau lebih media komunikasi seperti teks, grafik, animasi, audio, dan video dengan ciri intraktivitas komputer untuk menghasilkan satu presentasi menarik". Dapat dipahami bahwa media berbasis multimedia dapat menarik perhatian dan minat, lebih komunikatif, mudah dilakukan perubahan, interaktif, dan lebih leluasa menuangkan kreatifitas.

Pada hakikatnya IPA dibangun atas dasar produk ilmiah, proses ilmiah, dan sikap ilmiah. Karena itu IPA dianggap sebagai salah satu pelajaran yang sulit. Bagi tenaga pengajar IPA merupakan salah satu mata pelajaran yang membutuhkan alat peraga dan praktek. Sehingga hal tersebut menyulitkan bagi tenaga pengajar dalam proses pembelajaran. Hal ini terkendala oleh fasilitas laboratorium IPA ataupun alat peraga lainnya yang membantu proses pembelajaran khususnya pelajaran IPA.

Saat peneliti melakukan observasi dikelas Vb MI Darul Ulum Palangka Raya diketahui masih ada peserta didik yang memperoleh nilai di bawah standar ketuntasan. Dari seluruh peserta didik kelas Vb MI Darul Ulum Palangka Raya yang berjumlah 31 orang peserta didik $77 \%$ atau sebanyak (24 orang peserta didik) yang memperoleh nilai di atas nilai kriteria ketuntasan minimal (KKM). Sedangkan 23\% atau sebanyak (7 orang peserta didik) memperoleh nilai di bawah kriteria ketuntasan minimal (KKM). Adapun standar ketuntasan yang ditentukan sekolah untuk pelajaran IPA yaitu 60.

Menurut hasil wawancara dengan wali kelas $\mathrm{Vb}$ kegiatan belajar mengajar IPA terkadang menggunakan media pembelajaran, akan tetapi tidak adanya kalaborasi dengan pemanfaatan teknologi multimedia.

Peneliti melakukan penelitian pada kelas $\mathrm{Vb}$ pada mata pelajaran IPA dengan menggunakan penerapan media pembelajaran berbasis multimedia karena mempunyai alasan yaitu: (1) Peserta didik akan lebih mudah mencerna dan memahami apa yang dijelaskan guru (2) Tingkah pemahaman dan daya nalar peserta didik lebih tinggi sehingga mempermudah dalam proses pembelajaran (3) Pada usia anak-anak lebih tertarik dengan hal-hal yang cerah, bewarna, bergerak dan dengan tampilan menarik (4) Media multimedia sangat membantu dalam proses pembelajaran karena memiliki gabungan dari beberapa media seperti audio, visual, audio visual, teks, animasi, video, grafik, dan gambar (5) Media multimedia mudah didapat dan digunakan di kota dengan adanya listrik yang memadai, sehingga semuanya akan berjalan dengan baik tinggal bagaimana pemanfaatan teknologinya.

Pengertian belajar telah banyak dikemukakan oleh banyak ahli. Salah satu diantaranya Hirgard dan Brower (Hamalik,2010:45) "Belajar sebagai perubahan dalam perbuatan melalui aktivitas, praktek, dan pengalaman”.

Sadiman (2010:2) "Belajar adalah suatu proses yang kompleks yang terjadi pada semua orang dan berlangsung seumur hidup, sejak dia masih bayi hingga ke liang lahat".

Menurut Slamento (Djamarah, 2011:13) "Belajar adalah suatu proses usaha yang dilakukan individu untuk memperoleh suatu perubahan tingkah laku yang baru secara keseluruhan, sebagai hasil pengalaman individu itu sendiri 
dalam interaksi dengan lingkungannya". Sumadayo (2013:98) "Pembelajaran adalah suatu proses atau kegiatan guru dan siswa secara aktif, mencari dan menemukan pengetahuan melalui interaksi individu dengan lingkungan untuk memperoleh pengetahuan sendiri (Self Regulated)".

Berdasarkan pendapat para ahli di atas pembelajaran adalah suatu proses atau kegiatan guru dan siswa secara aktif, mencari dan menemukan pengetahuan melalui interaksi individu dengan lingkungan untuk memperoleh pengetahuan sendiri.

Menurut Kardi dan Nur (Trianto,2013:136) "IPA adalah ilmu tentang dunia zat, baik makhluk hidup maupun benda mati yang diamati”. Sedangkan menurut Carin dan Sund (Wisudawati dan Sulistyowati,2014:24) "Mendefinisikan IPA sebagai pengetahuan yang sistematis dan tersusun secara teratur, berlaku umum (universal), dan berupa kumpulan data hasil obsevasi dan eksperimen".

Media dalam pembelajaran sangat diperlukan dalam proses belajar mengajar. Karena media pembelajaran sangat berpengaruh dalam meningkatkan hasil pembelajaran.

Menurut Hainich, dkk (Jennah,2009:2) "Media pembelajaran adalah media-media yang membawa pesan-pesan atau informasi yang bertujuan pembelajaran atau mengandung maksudmaksud pembelajaran."

Menurut Turban dkk (Ariani dan Haryanto,2010:10) "Multimedia adalah kombinasi dari paling sedikit dua media meliputi input atau output. Media ini dapat berupa audio (suara, musik), animasi, video, teks, grafik, dan gambar".

Berdasarkan dari pendapat para ahli di atas, dapat disimpulkan multimedia adalah perpaduan dari beberapa media yang membentuk kesatuan yang utuh sehingga dapat menarik perhatian peserta didik.
Pada dasarnya semua media dibuat untuk mempresentasikan kepada sasaran yang dituju. Namun yang dibahas adalah mengenai media presentasi yang disajikan dengan program komputer melalui perangkat hardware yang berupa alat yang dikenal LCD proyektor. Pesan/materi yang dikemas berupa teks, gambar, animasi, suara, dan video yang dikombinasikan dalam satu kesatuan yang padu.

Dalam presentasikan pesan/materi berbasis multimedia menggunakan sebuah perangkat software. Nama-nama software itu banyak jenisnya antara lain microsoft word, microsoft excel, microsoft front page, microsoft power point, dan lain sebagainya. Dalam hal ini software yang digunaka adalah Microsoft power point yang dikeluarkan oleh perusahaan Microsoft Ins.

\section{METODOLOGI}

Ada pun waktu penelitian ini dilaksanakan dari bulan Januari sampai bulan Juni tahun pelajaran 2014/2015

Penelitian ini dilaksanakan di MI Darul Ulum Palangka Raya yang berlokasi di Jln. Dr. Murjani Gg Sari 45 RT 01/RW $X$ Kelurahan Pahandut, Kecamatan Pahandut, kota Palangka Raya. Alasan Peneliti meneliti di sekolah ini karena fenomena yang ada di sekolah sesuai dengan masalah penelitian.

Jenis penelitian yang dilakukan adalah penelitian tindakan kelas (PTK) yang dilakukan oleh pendidik di sekolah.

Menurut

Kunandar

(Iskandar,2010:21) "Penelitian tindakan (Action Research)merupakan suatu kegiatan yang dilakukan oleh guru atau bersama-sama dengan orang lain (kolaborasi) yang bertujuan untuk memperbaiki mutu proses pembelajaran di kelasnya". Menurut MCNiff (Kusumah dan Dwitagama,2012:8) "Penelitian tindakan kelas adalah sebagai bentuk penelitian reklektif yang dilakukan oleh guru sendiri yang hasilnya dapat dimanfaatkan sebagai alat untuk pengembangan keahlian mengajar". 
Berdasarkan dari pendapat para ahli di atas, dapat disimpulkan penelitian tindakan kelas merupakan tindakan yang dilakukan oleh guru kepada peserta didik dengan interaksi secara langsung yang terjadi didalam kelas.

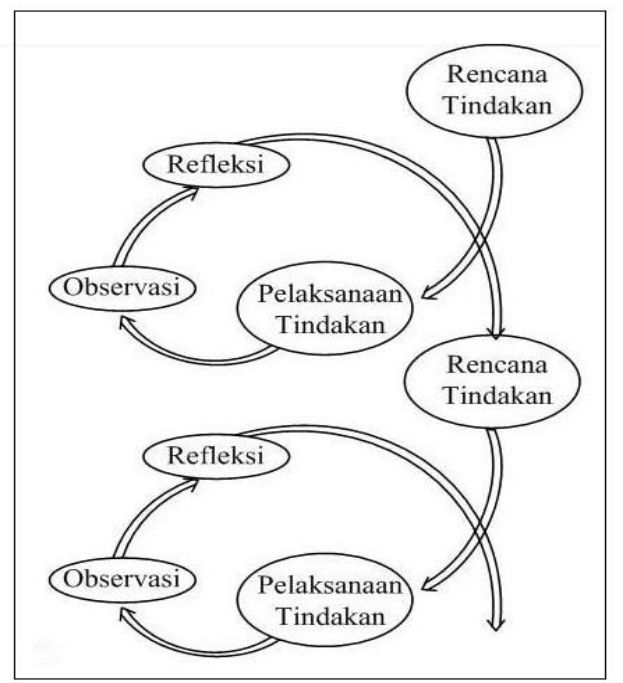

Gambar 1

Model Kemmis \& Taggart

Muslich (2009:91) "Analisis data adalah upaya memilih, memilah, membuang dan menggolongkan untuk menjawab dua hal pokok".

Menurut Bogdan dan Taylor (Iskandar,2012:74) "analisis data sebagai proses yang mencari usaha secara formal untuk menemukan tema dan merumuskan ide seperti yang disarankan oleh data dan sebagai usaha untuk memberikan bantuan pada tema dan ide itu".

Berdasarkan pendapat para ahli di atas dapat disimpulkan penelitian tindakan kelas adalah kegiatan yang dilakukan pendidik untuk merubah dan membaiki dalam proses pembelajaran.

Data kualitatif dalam penelitian ini diperoleh dari hasil lembar observasi yang dilakukan saat proses pembelajaran dengan memperhatikan aktivitas guru maupun aktivitas peserta didik sesuai dengan aspek-aspek yang telah disediakan. Hal ini dilakukan untuk mengetahui perubahan yang terjadi saat menerapkan pembelajaran media pembelajaran berbasis multimedia yang digunakan pada saat proses pembelajaran Ilmu Pengetahuan Alam (IPA) pada peserta didik kelas $\mathrm{Vb} \mathrm{MI}$ Darul Ulum Palangka Raya.

\section{HASIL DAN PEMBAHASAN}

Data pra tindakan bertujuan untuk mengetahui tingkat penguasaan peserta didik dalam materi yang akan dijadikan topik pembelajaran sebelum penelitian tindakan kelas dilaksanakan. Tes dilakukan dengan memberikan soal item pilihan ganda dengan jumlah 20 butir soal. Aktivitas Peserta didik

Dari hasil aktivitas peserta didik secara keseluruhan dengan rata-rata 2,95 dan hasil aktivitas peserta didik per individu 29,25, maka kriteria cukup dari indikator keberhasilan penelitian yaitu minimal mencapai secara keseluruhan 3,0 dan per individu 30 serta secara klasikal $85 \%$ peserta didik tuntas dalam aktivitas belajar.

Hasil Belajar

Dari post test siklus I terlihat hasil belajar peserta didik kelas Vb MI darul Ulum Palangka Raya dengan ketuntasan secara klasikal $83,87 \%$ termasuk dalam kriteria kurang tercapai dari indikator keberhasilan penelitian yaitu minimal secara individual 60 dan secara klasikal $85 \%$ peserta didik tuntas dalam belajar.

\begin{tabular}{|c|c|c|c|c|c|}
\hline & \multirow{2}{*}{$\begin{array}{c}\text { Kode } \\
\text { Neser } \\
\text { ta } \\
\text { Didik }\end{array}$} & $\begin{array}{c}\text { Nilai } \\
\text { Siklu } \\
\text { s I }\end{array}$ & $\begin{array}{c}\text { Nilai } \\
\text { Siklus } \\
\text { II }\end{array}$ & \multicolumn{2}{|c|}{ Ketunt asan } \\
\cline { 4 - 6 } & & & & \\
\hline 1 & AI & 75 & 100 & $\begin{array}{c}\text { Tidak } \\
\text { Tuntas } \\
=\leq 60\end{array}$ \\
\hline 2 & AR & 75 & 85 & $\checkmark$ & \\
\hline 3 & AS & 55 & 60 & $\checkmark$ & \\
\hline 4 & ER & 70 & 85 & $\checkmark$ & \\
\hline 5 & F & 70 & 80 & $\checkmark$ & \\
\hline 6 & G & 90 & 100 & $\checkmark$ & \\
\hline 7 & KH & 80 & 95 & $\checkmark$ & \\
\hline 8 & HR & 65 & 75 & $\checkmark$ & \\
\hline 9 & M & 85 & 100 & $\checkmark$ & \\
\hline
\end{tabular}




\begin{tabular}{|c|c|c|c|c|c|}
\hline \multirow[b]{2}{*}{$\mathrm{No}$} & \multirow{2}{*}{$\begin{array}{c}\text { Kode } \\
\text { Peser } \\
\text { ta } \\
\text { Didik }\end{array}$} & \multirow[b]{2}{*}{$\begin{array}{c}\text { Nilai } \\
\text { Siklu } \\
\text { s I }\end{array}$} & \multirow[b]{2}{*}{$\begin{array}{c}\text { Nilai } \\
\text { Siklus } \\
\text { II }\end{array}$} & \multicolumn{2}{|c|}{ Ketuntasan } \\
\hline & & & & $\begin{array}{l}\text { Tunt as } \\
=\geq 60\end{array}$ & $\begin{array}{l}\text { Tidak } \\
\text { Tunt as } \\
=\leq 60\end{array}$ \\
\hline 10 & MF & 65 & 75 & $\checkmark$ & \\
\hline 11 & MH & 55 & 65 & $\checkmark$ & \\
\hline 12 & MLA & 85 & 100 & $\checkmark$ & \\
\hline 13 & $\bar{M}$ & 75 & 80 & $\checkmark$ & \\
\hline 14 & $\mathrm{M}$ & 80 & 85 & $\checkmark$ & \\
\hline 15 & $\bar{M}$ & 75 & 90 & $\checkmark$ & \\
\hline 16 & $\mathrm{NS}$ & 55 & 80 & $\checkmark$ & \\
\hline 17 & NK & 75 & 85 & $\checkmark$ & \\
\hline 18 & $\bar{P}$ & 55 & 85 & $\checkmark$ & \\
\hline 19 & $\mathrm{PA}$ & 55 & 70 & $\checkmark$ & \\
\hline 20 & RW & 75 & 90 & $\checkmark$ & \\
\hline 21 & RY & 65 & 80 & $\bar{\checkmark}$ & \\
\hline 22 & RSZ & 70 & 80 & $\checkmark$ & \\
\hline 23 & $\begin{array}{c}\mathrm{RM} \\
\mathrm{M}\end{array}$ & 65 & 85 & $\checkmark$ & \\
\hline 24 & SA & 70 & 80 & $\checkmark$ & \\
\hline 25 & SS & 80 & 95 & $\checkmark$ & \\
\hline 26 & $\mathrm{SN}$ & 60 & 70 & $\checkmark$ & \\
\hline 27 & $S$ & 70 & 75 & $\checkmark$ & \\
\hline 28 & $S$ & 75 & 85 & $\checkmark$ & \\
\hline 29 & $S$ & 70 & 80 & $\bar{\checkmark}$ & \\
\hline 30 & $\overline{Y S}$ & 80 & 85 & $\checkmark$ & \\
\hline 31 & $\overline{\mathrm{ZN}}$ & 80 & 90 & $\checkmark$ & \\
\hline Jum & & 2200 & 2590 & \multirow{3}{*}{\multicolumn{2}{|c|}{ Sangat Tercapai }} \\
\hline Rat & rata & 70,96 & 83,54 & & \\
\hline & ntasan & $\begin{array}{c}83,87 \\
\%\end{array}$ & $\begin{array}{c}100, \\
\%\end{array}$ & & \\
\hline
\end{tabular}

Pada aktivitas guru pada siklus II telah terjadi menguasai ruangan saat menjelaskan materi pelajaran, memberikan pujian/hadiah saat peserta didik berhasil menjawab pertanyaan, mengorganisasikan peserta didik dalam kelompok-kelompok untuk diskusi,membimbing peserta didik dalam diskusi. Adapun penggunaan media multimedia terus diterapkan dalam menyampaikan materi pelajaran. Selain itu, penggunaan media multimedia juga dapat meningkatkan ketertarikan peserta didik dengan pelajaran selama proses pembelajaran yang secara tidak langsung juga akan meningkatkan hasil belajar peserta didik hal ini dapat terlihat dari hasil belajar peserta didik.

Sedangkan untuk aktivitas peserta didik untuk siklus II ini sangat lebih meningkat. Hal ini dapat dilihat dari jumlah nilai dari siklus II yaitu 3,75 secara keseluruhan dan per individu 37,09. Proses peningkatan aktivitas peserta didik dapat tercapai dilihat dari kriteria keberhasilan penelitian yang diterapkan yaitu jika aspek aktivitas peserta didik bisa mencapai 3,0 secara keseluruhan dan per individu 30 sedangkan secara klasikal minimal $85 \%$ dari peserta didik tuntas dalam belajar. Peningkatan keaktifan peserta didik diamati saat pembelajaran berlangsung.

Dari hasil belajar pada siklus II sangat mengalami peningkatan dari siklus I ini bisa dilihat dari hasil persentase yaitu 100\%. Ini dikarenakan seluruh peserta didik mencapai nilai KKM yaitu 60 . Indikator yang digunakan untuk mengukur peningkatan hasil belajar peserta didik adalah adanya peningkatan hasil belajar peserta didik baik secara klasikal maupun individual. Secara individual, peserta didik dinyatakan tuntas belajar jika telah mencapai tingkat pemahaman materi 65 yang ditunjukkan dengan perolehan nilai tes formatif 60 atau lebih. Kriteria yang digunakan untuk mengukur tingkat keberhasilan perbaikan pembelajaran adalah jika ada peningkatan hasil belajar secara klasikal dan individual, serta minimal $85 \%$ dari peserta didik tuntas dalam belajar, maka intervensi yang dilakukan dikatakan dapat meningkatkan hasil belajar peserta didik.

\section{KESIMPULAN}

Berdasarkan hasil penelitian yang telah dibahas maka dapat disimpulkan beberapa hal yaitu: 
1. Aktivitas belajar peserta didik kelas Vb MI Darul Ulum Palangka Raya lebih aktif pada saat pembelajaran Ilmu Pengetahuan Alam (IPA) dengan menggunakan Media Multimedia pada siklus I mencapai 2,95 dik ate gorikan cukup dan siklus II mencapai 3,75 dikategorikan baik.

2. Ada peningkatan hasil belajar IPA dengan Penerapan media Pembelajaran Berbasis Multimedia pada peserta didik kelas Vb MI Darul Ulum Palangka Raya. Hal ini terlihat dari data hasil belajar peserta didik pada siklus I mencapai $83,87 \%$ dan pada siklus II meningkat menjadi $100 \%$. Adapun standar ketuntasan yang ditentukan sekolah untuk pelajaran Ilmu Pengetahuan Alam (IPA) yaitu 60.

Dari hasil penelitian maka rekomendasi yang dapat diberikan sebagai berikut:

1. Bagi Kepala Sekolah, melakukan supervisi pada proses pembelajaran dan memberi saran dan masukan pada guru untuk menggunakan media multimedia melau alat LCD Proyektor dalam pembelajaran Ilmu Pengetahuan Alam (IPA) maupun pembelajaran yang lainnya.

2. Bagi Guru, menggunakan media multimedia melau alat LCD proyektor yang dalam pembelajaran Ilmu Pengetahuan Alam (IPA) maupun pembelajaran yang lainnya.

\section{DAFTAR PUSTAKA}

Djamarah, (2011). Pengertian Belajar dan Hasil

Belajar.http://Duniabaca.com.html. Diakses tanggal 03 Maret 2012

Fajar Shadiq, (2003).Penalaran,

Pemecahan Masalah dan Komunikasi dalam Pembelajaran
Matematika. Yogyakarta: PPPG

Matematika

Herman Hudojo, (2003).Pengembangan

Kurikulum dan Pembelajaran

Matematika. Malang: Jurusan

Matematika FMIPA UNM

Heruman, (2007). Model Pembelajaran

Matematika di Sekolah Dasar.

Bandung: PT Remaja Rosdakarya

Hollands, (1991).Kamus Matematika.

Jakarta: Penerbit Erlangga

Koesmartono, \& Rawuh,

(2001).Matematika Pendahuluan.

Bandung: ITB

Kunandar, (2010).Langkah Mudah

Peneltian Tindakan Kelas Sebagai

Pengembangan Profesi Guru.

Jakarta: PT RajaGrafindo Persada

Margono, (2009).Metodologi Penelitian

Pendidikan. Jakarta: PT Rineka

Cipta

Mohammad Asrori, (2008).Penelitian

Tindakan Kelas. Bandung: CV

Wacana Prima

Mustofa Usman, dkk, (2009).Statistik.

Bandung: PT Sinar Baru Algesindo

Riduwan, (2009). Metode dan Teknik

Menyusun Proposal Penelitian.

Bandung: Alfabeta

Sugiyono, (2007).Statistik untuk

Penelitian. Bandung: PT Alfabeta

Suharsimi Arikunto, (2006).Prosedur

Penelitian. Jakarta: PT Rineka Cipta

Suharsimi Arikunto, dkk,

(2009).Penelitian Tindakan

Kelas.Jakarta: PT Bumi Aksara

Ariani, Niken \& Haryanto, Dani. 2010.

Pembelajaran Multimedia di

Sekolah. Jakarta: Presentasi Pustaka 
Ars yad, Azhar. 2011. Media

Pembelajaran. Jakarta: PT

Rajagrafindo Persada

Djamarah,B.S. 2011. Psikologi Belajar. Jakarta: Rineka Cipta

Daryanto. 2010. Media Pembelajaran.

Yogyakarta: Gava Media

Hamalik, Oemar. 2010. Psikologi Belajar Mengajar. Bandung: Sinar Baru

Algensindo

Hari, Santoso. 2014. Upaya

Meningkatakan Hasil Belajar IPS

Menggunakan Metode Problem

Solving Pada Peserta Didik MIS

Darul Ulum Kota Palangkaraya.

Skripsi Universitas Muhammadiyah

Palangka Raya

Iskandar. 2012. Peneltian Tindakan Kelas.

Jakarta: Referensi (GP Press Group)

Jennah, Rodhatul. 2009. Media

Pembelajaran. Banjarmasin:

Antasari Press

Kusumah, W Mediijaya \& Dwitagama

Dedi. 2012. Mengenal Penelitian

Tindakan Kelas. Jakarta: PT Indekas

Permata Putri Media

Munir. 2013. Multimedia Konsep dan

Aplikasi dalam Pendidikan.

Bandung: Alfabeta

Munir. 2010. Kurikulum Berbaisi

Teknologi Informasi dan

Komunikasi. Bandung: Alfabeta

Munadi, Yudhi. 2013. Media

Pembelajaran. Jakarta: Referensi

(GP Press Group)

Muslick, Masnur. 2009. Melaksanakan PTK itu Mudah. Jakarta: Bumi Aksara
Rusman. 2013. Belajar dan Pembelajaran Berbasis Komputer. Bandung:

Alfabeta

Sadiman, dkk. 2010. Media Pendidikan

Pengertian, Pengembangan dan

Pemanfaatannya. Jakarta: Rajawali

Pers

Sudijono, Anas. 2012. Evaluasi

Pendidikan. Jakarta: PT Rajawali

Pers Raja Grafindo Persada

Sugiyono. 2010. Metode Penelitian

Pendidikan pendekatan kuantitaif,

kualitatif dan R\&D. Bandung:

Alfabeta

Sugiyono. 2014. Statistika untuk

Penelitian. Bandung: Alfabeta

Sumadoyo, Samsu. 2013. Penelitian

Tindakan Kelas. Yogyakarta: Graha Ilmu

Susanto, Ahmad. 2014. Teori Belajar dan Pembelajaran di Sekolah Dasar.

Jakarta: Kecana Prenademedia

Group

Sofrayani. 2014. Penggunaan Media LCD

Pada Pembelajaran. STAI

Darussalam Martapura: Jurnal

Darussalam

Suprihatingrum, Jamil. 2014. Strategi

Pembelajaran Teroti dan

Aplikasinya. Jogjakarta: Ar-Ruzz

Media

Trianto. 2013. Model Pembelajaran

Terpadu. Jakarta: Bumi Aksara

Tim Penyusun (2013), Buku Pedoman

Penulisan Skripsi, Palangkaraya

UMP

Warsita, Bambang. 2008. Teknologi Pembelajaran dan Aplikasinya. Jakarta: Rineka Cipta 